\title{
UNDERSTANDING HOW FIRST-YEAR SEMINARS AFFECT PERSISTENCE
}

\author{
Stephen R. Porter ${ }^{\star}$ and Randy L. Swing**
}

First-year seminars are nearly ubiquitous fixtures in American higher education, and research has documented their positive effect on student persistence. Only limited research, however, has attempted to isolate the impact of various aspects of firstyear seminars on persistence, especially on a cross-institutional basis. We use a survey of almost 20,000 first-year students at 45 four-year institutions combined with institutional-level data to understand how aspects of first-year seminars affect early intentions to persist. Because survey respondents are grouped within dissimilar institutions, we use a multilevel modeling approach to model intent to persist.

KEY WORDS: first-year seminars; persistence; multilevel models; course content; logistic regression.

"Over the past two decades, literally thousands of first-year programs have been created with increased retention rates as the primary, if not the sole, desired outcome" (Barefoot, 2000). The first-year seminar, one, such initiative, has grown to become a nearly ubiquitous component of American higher education (Gardner, 1986; Gordon, 1989). Results from a recent study by the Policy Center on the First Year of College reveal that $94 \%$ of accredited four-year colleges and universities in America offer a first-year seminar to at least some students and over half offer a first-year seminar to $90 \%$ or more of their first-year-students (Policy Center on the First Year of College, 2002).

\footnotetext{
*Educational Leadership and Policy Studies, Iowa State University, IA, USA.

**Policy Center on the First Year of College, Brevard College, 400 N. Broad St, Brevard, NC 28712.

$\dagger$ Address correspondence to: Stephen R. Porter, Educational Leadership and Policy Studies, N232-A Lagomarcino Hall, Iowa State University, Ames, IA 50011-3195. E-mail: srporter@ iastate.edu
} 
Institutional attention to persistence rates and the development of first-year seminars have emerged for a variety of reasons, including (1) financial exigency, either, to keep tuition-paying students enrolled or to meet the demands of budget-connected, state-mandated performance indicators; (2) reputation enhancement, such as improving rank in U.S. News and World Report, which uses first-year retention rate as a factor in their annual college rankings; (3) perceived advantage in admissions, marketing, and fundraising as retention rate has, for better or worse, become a de facto measure of institutional quality; and (4) mission fulfillment, because graduating students is a marker of success in producing an educated citizenry and a necessary step for reaching a wide array of educational goals.

Whether institutions undertake persistence enhancement programs for intrinsic or extrinsic reasons, their success has tremendous impact on institutions of higher education, students, and families of students. Given the strong emphasis on these courses in the collegiate experience, as well as the resources that institutions expend to provide them, it is important that we understand how first-year seminars affect student persistence.

It has been reported that first-year seminars have become the most studied higher education innovation (Barefoot, Warnock, Dickinson, Richardson, and Roberts, 1998) and that, generally, they do appear to have a positive impact on persistence (Cuseo, 1991; Pascarella and Terenzini, 1991). Still, there is much not known about the impact of first-year seminars because so much of the existing research on these courses is limited to single-institution studies, and because much of the research focuses on the impact of these courses overall, rather than what specific aspects of the course affect persistence.

We investigate first-year seminars and the impact of course content on early intent to persist using a survey of students in first-year seminars at 45 four-year colleges and universities. Because we have data for 45 institutions, we use a multilevel modeling approach to estimate the effects of the first-year seminar content on early intention to return for the second year of college. We seek to answer one question: what specific content areas of first-year seminars lead to greater intent to persist among first-year students?

\section{LITERATURE REVIEW}

About $16 \%$ of students who enter a four-year institution leave during the first year or do not return for their second year (Horn, 1998). Most students who leave do so only temporarily, as, $64 \%$ return to a college within 6 years, but these students are generally at a disadvantage in that 
they either experience a longer time to degree or are less likely to earn a bachelor's degree (Choy, 2002). Clearly, stopping out, dropping out, or transferring out has a negative impact on the cost of higher education and degree attainment rates.

Institutions have developed an array of first-year attrition intervention programs, such as first-year seminars, to encourage student success in the first year. A large body of literature indicates that first-year seminars have a positive impact on student academic and social integration, key concepts of persistence proposed by Tinto (1975, 1993). For example, researchers have shown that seminar participants earn, on average, higher grades in other first-year classes and are less likely to be placed on academic probation (Cannici and Pulton, 1990; Chapman and Reed, 1987; Davis, 1992; Fidler, 1991; Williford, Chapman, and Kahrigh, 2000-2001); they have higher frequencies of participation in campus activities or services (Cannici and Pulton, 1990; Davis-Underwood and Lee, 1994; Fidler, 1991); and they report more out-of-class connections with faculty members (Davis-Underwood and Lee, 1994; Fidler, 1991; Maisto and Tammi, 1991).

Other studies have investigated how student characteristics impact the outcomes of first-year seminars. For example, the mentoring aspects of seminars appear to work better for females than for males (Blackhurst, 1995). Additionally, the impact of first-year seminars on persistence seem to vary based on the SAT/ACT scores of students (Hyers and Joslin, 1998, Davis, 1992).

Not surprisingly, a large collection of research focuses on student persistence, a common goal of first-year seminars (Barefoot, 2000). Usually researchers use enrollment records connected with curriculum records to compare the persistence rate for first-year seminar students with the persistence rate for students who did not enroll in a first-year seminar. Most studies show a positive gain in persistence for students who enroll in the course (Bedford and Durkee, 1989; Fidler and Moore, 1996; Hyers and Joslin, 1998; Murtuza and Ketkar, 1995; Pascarella and Terenzini, 1991; Strumpf and Hunt, 1993; Williford et al., 2000--2001). For example, a longitudinal study of "University 101" at the University of South Carolina, a "model" course ranked by U.S. News and World Report (2002) as one of the best first-year seminars in America, showed positive retention rates for 11 of the 16 years studied (Fidler, 1991).

Despite research showing the impact of first-year seminar participation on persistence, our understanding of these courses is limited by the lack of research that disaggregates the many components of first-year seminars. It is not clear which course content/components (e.g., an emphasis on study skills, explanations of campus policies and procedures, 
encouragement for students to become involved in the campus) most contribute to increased persistence. Like any college course, first-year seminar teachers must choose which topics to include or exclude and how much weight to give to each selected topic. Understanding which aspects of a first-year seminar have the greatest impact on persistence could inform course administrators and instructors about where to concentrate their efforts.

Research on first-year seminars must not, however, be restricted only to variables that the institution controls, as student characteristics have also been shown to influence the outcomes of educational interventions. For example, there is general agreement in the literature that males (Leppel, 2002; Mortenson, 2001), students with weak academic backgrounds (Astin, 1993; U.S. Department of Education, 2001), or students who work off campus more than 15 hours per week (Choy, 2002) have lower persistence rates. Understanding the effect of first-year seminar components can only be accomplished when controlling for student characteristics, so that the effect of course components are isolated from the effect of student characteristics.

Institutional characteristics also potentially impact how first-year seminars affect persistence, since they are associated with different persistence rates. It is thus important to also control for institutional characteristics. Institutional characteristics such as institution type $(\mathrm{Hu}$ and St. John, 2001), private sector (Hu and St. John, 2001; Ryan, 2004), selectivity (Kim, Rhoades and Woodard, 2003) and spending per student (Porter, 2000; Ryan, 2004) have been shown to positively affect persistence and graduation rates.

A full research model of first-year seminars aimed at exploring the impact of course components should include measures of course components as well as control variables for both student and institutional characteristics. To date, there is virtually no published research that has attempted a cross-institutional research model to explore how first-year seminar course components affect any course goals, including persistence. Given the wide-spread adoption of first-year seminars and the substantial investment of resources they represent, understanding how to best target course components to achieve desired outcomes is much needed.

\section{DATA AND METHODOLOGY}

\section{The First-Year Initiative Survey}

The data for this study were collected at the end of the fall 2001 semester using the First-Year Initiative (FYI) survey. This survey was 
designed to provide participating campuses with aggregated student self-reports of the learning outcomes from participation in a one-term first-year seminar. The purpose of the survey was to give institutions formative evaluations of their first-year seminars in a way that would encourage continuous improvement. Funding for the survey was provided by the Atlantic Philanthropy and The Pew Charitable Trusts, and the survey was administered by Educational Benchmarking, Inc.

The 2001 FYI survey administration was underwritten by grants so there were no costs for institutions to participate. An open call for institutional participation was announced through various listservs and conference presentations. Institutions applied for one of an estimated 50 slots in the 2001 survey administration by writing a brief report about their first-year seminar. Baseline selection criteria included enrollment of at least 150 students in a fall 2001 first-year seminar, and a commitment to either survey $100 \%$ of seminar students or use a systematic sampling procedure. To maximize the variation of institutional types and geographic spread, 61 institutions were selected to reflect the percent of institutions in the United States by Carnegie Classification.

Telephone appointments were scheduled with the survey coordinator at each participating campus to collect detailed institutional and course information. Researchers determined the percent of seminar sections that best fit each of four defined seminar types (see Table 1). Courses were coded at the institutional level if at least $75 \%$ of sections were of the same type. Four institution-level codes were used: (l) college success/ transition theme, (2) special academic theme, (3) themes connected to academic or professional disciplines, or (4) remedial theme. An institution was labeled "mixed" if less than $75 \%$ of the sections were of the same form. The coding revealed that the most common format for the first-year seminar was the transition theme. This finding is consistent with data collected by the University of South Carolina's survey of firstyear seminars (National Resource Center for the First-Year Experience and Students in Transition, 2002).

The 61 selected institutions produced 31,755 student surveys. Institutions reported the number of students originally enrolled in each section of first-year seminar so it was possible to determine that $53 \%$ of students enrolled in these courses returned a useable survey.

To ensure homogeneity in course formats, the data for this study were limited to the 45 institutions where $75-100 \%$ of the sections offered were of the transition format. In addition, these courses were selected because they represent the most popular first-year seminar form. By limiting the data to institutions where the majority of courses are similar in format, we ensure that course-level data reflect the 
TABLE 1. Institutional Coding of Seminar Types

Seminar Types

Description

Transition theme

These courses focus on topics that ease the transition to college, develop skills needed for academic success, and encourage student engagement in the full range of educational opportunities

Special academic theme These courses focus on interdisciplinary themes other than college transition. While college adjustment and study skills may be included in the course, the majority of assignments and course time is spent exploring a selected topic.

Discipline theme These courses are administered by individual academic departments or units. They may serve as an introduction to a major or discipline. Students are recruited into these courses, at least in part,

because of interest in a major related to the course theme.

Remedial theme These courses are offered for students at high risk of dropping out or having low academic success and usually include intensive focus on study skills and life management skills.

Mixed format If fewer than $75 \%$ of first-year sections share one of the four theme-forms listed above, the institution is considered to use a "mixed-theme format."

Note: These definitions were developed by Randy Swing, Betsy Barefoot, John Gardner, and Joe Pica. They are an adaptation of definitions used by Betsy Barefoot in the 1991 Survey of First-Year Seminars conducted by the National Resource Center on The First-Year Experience and Students in Transition.

first-year seminar at the institution level. The final data set contained 20,031 respondents.

All but one of the selected institutions conducted the survey in class during the final two weeks of the fall term; one institution used a webbased version of the survey. Names and identifying information were not collected on the survey to ensure that students felt free to provide their honest opinions. Basic student demographic data were collected directly on the survey form.

\section{Statistical Approach}

We use a multilevel modeling approach to estimate the impact of specific elements of first-year seminars on intent to persist. Multilevel models offer several advantages over traditional ordinary least squares 
(OLS) when analyzing grouped data, where observations are grouped within organizational units (the data here are grouped, as the data consist of a survey of students across 45 institutions). In this particular application, the main advantage of using a multilevel model is the explicit recognition that while we may have observations for thousands of students, we have only 45 observations for schools.

This is important because of how OLS estimates the standard errors for the model coefficients. With an OLS approach, where school-level variables have been attached to individual student observations, OLS estimates the standard errors for the school-level variables using the student $\mathrm{N}$. It thus becomes relatively easy to find statistically significant school-level variables, because OLS incorrectly assumes that there are many school observations. Conversely, a multilevel model correctly estimates the standard errors for school-level variables (Heck and Thomas, 2000; Raudenbush and Bryk, 2002). The multilevel approach can thus be viewed as more conservative than OLS, because with only 45 observations and several school-level independent variables, the degrees of freedom used for estimating statistical significance at the school-level are much smaller than the degrees of freedom used by OLS.

The multilevel approach offers a second advantage over OLS models. When using survey data to construct a measure of course effectiveness, one can question how objective the measure truly is. Respondents might be affected by incidents that happened in the course that day, or perhaps were simply feeling unwell when they took the survey, resulting in a rating of course effectiveness that would be quite different from the "true" rating of course effectiveness.

One solution would be to average the student ratings across a school and use this average as a more objective measure of course effectiveness. Although students might deviate positively and negatively from the school mean, if students in a school on average give the firstyear seminar a high rating, we can be fairly confident that the course is indeed effective in a particular content area. Aggregation of individual perceptions offers a better measure of course effectiveness, and multilevel models can be used to estimate the impact of institutionallevel variables derived from individual survey data.(e.g., Jonge, Gerard, Landeweerd, and Nijhuis, 1999; Hoffman and Gavin, 1998). While OLS can also be used, multilevel models have more efficient estimators and correctly estimated standard errors (Raudenbush and Bryk, 2002, p. 141). 


\section{MODEL}

\section{Dependent Variable}

Our dependent variable is the student's intent to persist, as measured by their response to the question, "For the next academic year, to what degree do you plan to return to this college/university?" Respondents were given a seven-point Likert scale for answering the question, with responses ranging from 1 (not at all) to 7 (significantly). The distribution for this measure is presented in Table 2 . While approximately twothirds of the respondents chose 7, the most definite response, one-third chose a response indicating they were uncertain whether they would persist at their institution. Because the dependent variable is not normally distributed, we collapsed the seven categories in two categories, classifying students who selected a 6 or 7 response on the scale as retained, and all other students as not retained.

An alternative approach to dichotomizing the dependent variable would be to keep the variable in its original form and estimate an ordinal logistic regression. Unfortunately such a model cannot be estimated within a multilevel context on this particular dataset, given the small number of cases in some categories for some schools. By dichotomizing we lose some information about persistence. To understand what impact this might have on our results, we also estimated a standard multilevel regression using the original scale. The results from this model are similar to the results presented here.

TABLE 2. Distribution of the Dependent Variable (Intent to Persist in College)

\begin{tabular}{|c|c|c|c|c|c|c|}
\hline \multirow[b]{2}{*}{ Label } & \multicolumn{3}{|c|}{ Original Distribution } & \multicolumn{3}{|c|}{ Dichotomized Distribution } \\
\hline & Scale & $\%$ & $\mathrm{~N}$ & Scale & $\%$ & $\mathrm{~N}$ \\
\hline \multirow[t]{3}{*}{ Not at all } & 1 & 5.1 & 1,017 & & & \\
\hline & 2 & 2.1 & 422 & & & \\
\hline & 3 & 2.8 & 562 & & & \\
\hline \multirow[t]{3}{*}{ Somewhat } & 4 & 6.4 & 1,277 & & & \\
\hline & 5 & 6.9 & 1,379 & 0 & 23.2 & 4,657 \\
\hline & 6 & 12.2 & 2,438 & & & \\
\hline \multirow[t]{2}{*}{ Significantly } & 7 & 64.6 & 12,936 & 1 & 76.8 & 15,374 \\
\hline & & & 20,031 & & & 20,031 \\
\hline
\end{tabular}

Question: For the next academic year, to what degree do you plan to return to this college/ university? 
The intraclass correlation (Snijders and Bosker, 1999) reveals that $2.5 \%$ of the variance in this measure exists between colleges. This amount of variance between institutions may seem too small to analyze. We offer three reasons why this is not the case.

First, the implicit benchmark in this situation is $100 \%$; viewed in this manner, $2.5 \%$ does indeed seem small. Yet in practice the actual variance that can be explained by models in higher education never approaches $100 \%$ with individual-level data, and with survey data rarely exceeds $30 \%$. Indeed, we have seen articles where the author(s) explain only $5 \%$ of the variance with a dozen or more independent variables (e.g., Toutkoushian and Smart, 2001). Thus $2.5 \%$ is not an insubstantial amount of variance when viewed in the context of individual-level survey data, which contains large amounts of random error.

Second, consider how much variance is explained by a single individual-level variable in the typical regression model using survey data. Often this percentage is quite small, but we would not exclude the variable because it alone explains only a small portion of the variance. Instead, we focus on the effect of the variable. As discussed later in the paper, the effect of the school-level course variables is not insubstantial: a one SD change leads to a $14-16 \%$ increase in the probability that a student expresses an intent to return to their college.

Third, interesting level 2 effects have been found even when the intraclass correlation is quite small. For example, $\mathrm{Hu}$ and $\mathrm{Kuh}$ (2003b) found a statistically significant effect for selectivity on a dependent variable with a intraclass correlation of $3.3 \%$, while Merlo et al. (2001) found statistically significant level 2 effects for a dependent variable with an intraclass correlation of only $0.4 \%$.

Given that we use intent to persist as our dependent variable, rather than actual persistence, a discussion of the validity of our measure is in order. Substantial research has confirmed that asking students their intention to persist is one of the best predictors of actual persistence in the future (Bean, 1982; Cabrera, Castaneda, Nora and Hengstler, 1992; Cabrera, Nora and Castaneda, 1992; Nelson, Scott and Bryan, 1984; Okun, Benin and Brandt-Williams, 1996). We can also test the validity of our measure at the institutional level by comparing the mean level of our dichotomized intent to persist variable for each of the 45 schools in our sample and the actual one-year retention rate for this cohort of students. The correlation between these two measures is 0.57 . This relatively strong relationship at the institutional level indicates that the intent to persist question in the FYI survey is a reasonable proxy for actual persistence. 


\section{Independent Variables}

Descriptive information for the independent variables is presented in Table 3. Because we are estimating the impact of school-level attributes of first-year seminars on intent to persist, it is crucial that we control for differences between schools in student body composition and institu-

TABLE 3. Descriptives for Independent Variables

\begin{tabular}{|c|c|c|c|c|}
\hline & Mean & SD & Min & $\operatorname{Max}$ \\
\hline \multicolumn{5}{|l|}{ Individual-level } \\
\hline High school grades & 3.597 & 1.141 & 0 & 5 \\
\hline Work hours & 1.189 & 1.643 & 0 & 6 \\
\hline On-campus apartment & 0.017 & 0.131 & 0 & 1 \\
\hline Off-campus-without family & 0.178 & 0.383 & 0 & 1 \\
\hline Off-campus-with family & 0.064 & 0.244 & 0 & 1 \\
\hline Greek housing & 0.005 & 0.068 & 0 & 1 \\
\hline Other residence & 0.005 & 0.070 & 0 & 1 \\
\hline Female & 0.574 & 0.494 & 0 & 1 \\
\hline Black & 0.107 & 0.309 & 0 & 1 \\
\hline Asian & 0.016 & 0.124 & 0 & 1 \\
\hline Native American & 0.009 & 0.096 & 0 & 1 \\
\hline Hispanic & 0.037 & 0.189 & 0 & 1 \\
\hline Multi-racial & 0.017 & 0.131 & 0 & 1 \\
\hline Race/ethnicity unknown & 0.028 & 0.166 & 0 & 1 \\
\hline International student & 0.014 & 0.116 & 0 & 1 \\
\hline $\begin{array}{l}\text { Course-study skills and } \\
\text { academic engagement }\end{array}$ & 0 & 1 & -4.215 & 3.765 \\
\hline Course college knowledge & 0 & 1 & -3.958 & 3.607 \\
\hline Course-campus engagement & 0 & 1 & -3.765 & 3.867 \\
\hline Course-peer connection & 0 & 1 & -4.415 & 3.823 \\
\hline Course-health education & 0 & 1 & -3.021 & 3.409 \\
\hline \multicolumn{5}{|l|}{ School-level } \\
\hline Acceptance rate & 0.761 & 0.119 & 0.510 & 1 \\
\hline Spending per-student $(\$ 1,000 s)$ & 12.386 & 5.236 & 5.692 & 29.014 \\
\hline Public & 0.822 & 0.387 & 0 & 1 \\
\hline Doctoral & 0.378 & 0.490 & 0 & 1 \\
\hline Masters & 0.489 & 0.506 & 0 & 1 \\
\hline $\begin{array}{l}\text { Course-study skills and } \\
\text { academic engagement }\end{array}$ & 0.021 & 0.282 & -0.742 & 0.850 \\
\hline Course-college knowledge & -0.002 & 0.381 & -1.213 & 0.648 \\
\hline Course-campus engagement & -0.067 & 0.396 & -1.463 & 0.412 \\
\hline Course-peer connection & 0.028 & 0.265 & -0.611 & 0.855 \\
\hline Course-health education & -0.082 & 0.337 & -0.826 & 0.547 \\
\hline
\end{tabular}


tional attributes that might be confounding factors. We include two sets of independent variables to control for these differences (see Table 3 for descriptive information); all are taken from the FYI survey.

\section{Control variables}

The first set of variables measures attributes of individual students in three areas: academic preparation, finances, and demographics. These are some of the most common independent variables used in the persistence literature. To control for differences in academic preparation, we use a student's self-reported average high school grades (measured as an interval scale where $0=$ lower than a $\mathrm{C}$ and $5=$ mostly As). The more common measure of academic background, standardized test scores, was not asked in the survey. While the survey did not ask specific questions about financial circumstances, we include several variables that act as proxies for differences in financial background. The first, hours worked per week during college, is an interval scale where $0=$ no hours worked and $6=$ more than 25 hours a week worked. Because finances often determine where a student lives, we include a set of dummy variables indicating where students reside, with residence hall as the base category. Finally, to control for differences in the demographic makeup of the student body, we include dummy variables for gender, race/ethnicity, and whether the student was an international student.

Because of our estimation approach, we are somewhat constrained by the number of school-level variables that we can include in our models: the $\mathrm{N}$ at the school-level is only 45 . We chose five school-level variables to control for some of the most important differences between institutions: selectivity, resources, and mission. The first measure, selectivity, is the percentage of students admitted, taken from the U.S. News and World Report rankings for the class entering in 2001. The second, spending per student, is measured by the amount of money spent on instruction, academic support, student services, and institutional support divided by the FTE undergraduate student body. Three dummy variables measure the institution's sector (public versus private) and mission (Carnegie classification of doctoral or masters). These last four variables are taken from the Integrated Postsecondary Education Data System surveys (Fall Enrollment, Finance and Institutional Characteristics).

\section{First-year seminar variables}

Our measures of course content effectiveness are derived from a battery of 34 questions on the FYI survey (see Table 4). The questions 
TABLE 4. Survey Items and Course Scales

Factors and items

Alpha

Study skills and academic engagement

Consider how this class affected your other courses. Taking this

class increased the degree to which I...

Participated in classrooms discussions

Reviewed my class notes before the next class meeting

Prepared for tests well in advance

Completed homework assignments on time

Sought feedback from my instructors

Studied with other students

Established an effective study schedule

Coped with test anxiety

Set priorities so I can accomplish what is most important to me

Campus policies

Taking this class improved my understanding of...

College/university rules regarding academic honesty

Rules regarding plagiarism

The grading system

Academic probation policy

Registration procedures

Financial aid procedures

Health center services

Faculty expectations of students

The role of my academic advisor

The process of selecting a major

Importance of establishing personal goals

How to obtain academic assistance (tutors/mentors/etc.)

Career decision-making processes

Campus engagement

Taking this class increased the degree to which I...

Assumed leadership roles in campus-sponsored organizations.

Volunteered my time for worthwhile causes.

Attended campus cultural events.

Peer connections

Taking this class improved, my...

Efforts to get to know students in my classes

Ability to meet new people

Ability to establish close friendships

Health education

Taking this class improved my understanding of the ...

Importance of a healthy diet

Impact of alcohol consumption 
TABLE 4. (Continued)

Factors and items

Alpha

Impact of drug use

Importance of exercising regularly

are grouped into five scales measuring learning outcomes of first-year seminars. These scales are study skills and academic engagement, college policies, campus engagement, peer connections, and health education. The questions and scales were used because they represent topics generally covered in transition-format seminars.

For missing data on the questions used for our first-year seminar course scales, we adopted a compromise approach combining listwise deletion and imputation. We did not impute all missing data for two reasons. First, imputing data for all missing items within schools using sample means would have resulted in a reduction of variance in school means, while using school means instead of sample means might have had the effect of exaggerating school differences. Second, our approach is in line with recent research indicating listwise deletion may be the preferable way to deal with missing data (Allison, 2002). For scales with less than 10 items, respondents were included in the sample if they left 1 or 0 items blank. For scales with 10 or more items, respondents were included if they left 2 or fewer items blank. Missing items used in the course scales were then imputed with overall sample means.

As seen in Table 3, there are two sets of course effectiveness variables. The first set of variables is at the student level and is simply each individual student's factor score for the five scales. We take the average of these individual scores for each of the 45 schools in the study to create a second set of course effectiveness scales at the school level. It is these scales that are of primary interest, as they can be viewed as more objective measures of school-level course effectiveness than individual student ratings.

\section{RESULTS}

Table 5 presents the intent to persist model results. All variables except the intercept are fixed. Model 1 estimates the impact of the student-level and school-level control variables, while Model 2 includes the student-level and school-level measures of first-year seminar course effectiveness. The coefficients are multilevel model estimates with a 
TABLE 5. Intent to Persist Multilevel Model Estimates

\begin{tabular}{|c|c|c|c|c|}
\hline & \multicolumn{2}{|c|}{ Model 1} & \multicolumn{2}{|c|}{ Model 2} \\
\hline & $\mathrm{B}$ & SE & $\mathrm{B}$ & SE \\
\hline \multicolumn{5}{|l|}{ Individual-level } \\
\hline Intercept & 1.1239 & $0.0511 * * *$ & 1.1642 & $0.0390 * * *$ \\
\hline High school grades & 0.1659 & $0.0164 * * *$ & 0.1709 & $0.0176^{* * *}$ \\
\hline Work hours & -0.0214 & 0.0142 & -0.0232 & 0.0143 \\
\hline On-campus apartment & 0.3004 & $0.1201 * *$ & 0.2932 & $0.1140 * *$ \\
\hline Off-campus-with family & 0.3452 & $0.0532 * * *$ & 0.3846 & $0.0509 * * *$ \\
\hline Off-campus-without family & 0.0050 & 0.0590 & 0.0061 & 0.0573 \\
\hline Greek housing & -0.4812 & $0.2809^{*}$ & -0.4891 & $0.2880^{*}$ \\
\hline Other residence & -0.2485 & 0.1976 & -0.2017 & 0.2042 \\
\hline Female & 0.2717 & $0.0401 * * *$ & 0.2495 & $0.0413 * * *$ \\
\hline Black & -0.1417 & $0.0588 * *$ & -0.2123 & $0.0615 * * *$ \\
\hline Asian & -0.3120 & $0.1354 * *$ & -0.3382 & $0.1359 * *$ \\
\hline Native American & -0.0520 & 0.1735 & -0.0735 & 0.1877 \\
\hline Hispanic & -0.0095 & 0.1193 & -0.0572 & 0.1206 \\
\hline Multiracial & -0.3850 & $0.1015 * * *$ & -0.3869 & $0.1062 * * *$ \\
\hline Race/ethnicity unknown & -0.3691 & $0.1090 * * *$ & -0.3656 & $0.1100 * * *$ \\
\hline International student & -0.0671 & 0.1870 & -0.1260 & 0.1866 \\
\hline Course-study skills & & & 0.1317 & $0.0196 * * *$ \\
\hline Course-campus policies & & & 0.2482 & $0.0241 * * *$ \\
\hline Course-campus engagement & & & 0.0622 & $0.0199 * * *$ \\
\hline Course-peer connection & & & 0.1825 & $0.0181 * * *$ \\
\hline Course-healthy lifestyle & & & 0.1295 & $0.0220 * * *$ \\
\hline \multicolumn{5}{|l|}{ School-level } \\
\hline Acceptance rate & -0.5232 & 0.3917 & -0.3352 & 0.3232 \\
\hline Spending per student $(\$ 1,000 \mathrm{~s})$ & -0.0153 & 0.0134 & -0.0032 & 0.0119 \\
\hline Public & 0.0964 & 0.2250 & 0.1001 & 0.1593 \\
\hline Doctoral & 0.4495 & $0.2232 *$ & 0.4818 & $0.1829 * *$ \\
\hline Masters & 0.2957 & 0.1763 & 0.4583 & $0.1464 * * *$ \\
\hline Course-study skills & & & 0.6735 & $0.3125^{* *}$ \\
\hline Course-campus policies & & & -0.1232 & 0.1344 \\
\hline Course-campus engagement & & & -0.2684 & 0.2323 \\
\hline Course-peer connection & & & 0.1779 & 0.1185 \\
\hline Course healthy lifestyle & & & 0.5735 & $0.2632 * *$ \\
\hline
\end{tabular}

Note: Results are population-average coefficients with robust standard errors. ${ }^{*} p<.10$; $* * p<.05 ; * * * p<.01$.

Bernoulli sampling model and logit link function, and are similar to the traditional dichotomous logistic regression model used in much of the general literature on retention. 
We can see that the impact of the control variables fits with the general findings in the persistence literature. Students with better grades in high school as well as females are more likely to express an intention to return to their institution the following year, while students who work many hours during the week are less likely to say they will return. At the institutional level, neither selectivity nor resources are significantly related to intent to persist after controlling for student characteristics at the individual level. Students at doctoral institutions indicate a higher intent to return than students at liberal arts colleges.

Turning to the course variables in Model 2, we can see that at the student level all five factors are statistically significant with positive coefficients. Individual perceptions matter: as students rate their course as more effective in a given content area, they are slightly more likely to express an intent to return. However, the substantive impact is small. Table 6 presents the changes in the probability of intent to return, given a one standard deviation change in the course effectiveness scale. If students' individual perceptions of course effectiveness in a topic area increase one standard deviation from their peers in rating the effectiveness of a course, their probability of indicating an intent to persist will only increase about 1-6 percentage points. The campus policies scale has the largest impact at 6 percentage points.

Some of the school-level means, however, have a stronger substantive impact on intent to persist. Recall that as aggregated perceptions these means can be viewed as a more objective measure of course effectiveness in the five topic areas, compared with individual student perceptions. Of the five measures, only study skills and health education have coefficients statistically different from zero. These results indicate that students at schools with first-year seminars that do a good job in imparting study skills and educating students in health matters have

TABLE 6. Change in Probablity of Intent to Return

\begin{tabular}{lcc}
\hline & \multicolumn{2}{c}{ Impact of 1 SD change in factor } \\
\cline { 2 - 3 } Factor & Student level & School-level \\
\hline Study skills & $3.2 \% * *$ & $15.7 \% *$ \\
Campus policies & $6.1 \% * *$ & $-3.1 \%$ \\
Campus engagement & $1.5 \% * *$ & $-6.7 \%$ \\
Peer connection & $4.5 \% * *$ & $4.4 \%$ \\
Health information & $3.2 \% * *$ & $13.6 \% *$ \\
\hline
\end{tabular}

Note: Calculated from coefficients in Table $5 .{ }^{*} p<.05 ;{ }^{*} p<.01$. 
higher mean probabilities of intent-to persist, even after controlling for selectivity, resources, institution type, individual perceptions of course effectiveness, and student characteristics.

The substantive impact of these two measures is not inconsequential. For every standard deviation change in the average rating of effectiveness in study skills and health education, an individual student's intent to persist will increase 16 and 14 percentage points, respectively. The results indicate that choice of content in first-year seminars may indeed make a difference, especially when they are effective in specific content areas.

\section{LIMITATIONS}

Our study has several limitations, mostly due to the use of data which were generated for purposes other than this research project. First, like many other national student surveys such as the CIRP, CSEQ, and NSSE, we have a convenience sample of institutions rather than a random sample of all U.S. institutions. Because colleges and universities self-selected into the sample, we may have truncated variance in firstyear programs. It is possible that only institutions that value first-year seminars chose to participate in an activity aimed at improving the courses. In addition, only four-year institutions were invited to participate. First-year seminars do exist at two-year institutions; our findings cannot be generalized to first-year seminars at these schools.

Second, we lack a control group of students who did not participate in a first-year seminar. Thus we can only investigate the contribution of various dimensions of the first-year seminar experience compared to other first-year seminars, and not compared to students who were not exposed to these dimensions.

Third, our dependent variable is intent to persist rather than actual persistence outcomes. While a reasonable proxy, a follow-up study using actual persistence outcomes would be much preferable. Actual outcomes over the course of a student's career would be especially helpful in understanding how first-year seminars affect persistence after the second year of school. However, the FYI survey is similar to an end of term course evaluation in that students must be free to honestly evaluate their experiences. Student identifiers that would allow linking to institutional databases in order to track actual outcomes might possibly compromise other important aspects of similar research.

Fourth, similar to much of the literature on student development and engagement (e.g., $\mathrm{Hu}$ and $\mathrm{Kuh}, 2002$, 2003a; Kuh and $\mathrm{Hu}, 2001$; Zhao and Kuh, 2004), our study lacks pre-college measures, standardized test 
scores and explicit financial aid variables. We used instead selectivity to control for differences in the student body across institutions. Given the impact of finances on persistence, we relied on student residence and work hours as proxies for financial status.

Fifth, we rely on student self-reports for the effect of first-year seminars in specific course content areas. Future work in this area could include course content measures based on the actual structure of the course, using perhaps course syllabi or survey data collected from instructors.

Sixth, while first-year seminar variables can be course specific, we treat them as institution-specific. Undoubtedly the course effectiveness scales that we developed vary not only between but also within institutions. Future work in-this area should consider three-level multilevel models, where students are nested within courses, which in turn are nested within institutions.

Finally, with 10 independent variables at the school-level, we are pushing the limits of what the data can tell us about institutional effects and intent to persist. This is due to the unfortunate lack of cross-institutional data on first-year seminars. Given the number of variables that could plausibly be used as predictors at the school-level, much larger datasets with greater numbers of schools would be preferable in future research.

\section{DISCUSSION}

This research effort is an addition to the current literature on firstyear seminars and persistence because we investigate which aspects of first-year seminars affect persistence while using a multi-institutional dataset to estimate their impact across a range of institutional settings.

Using a survey of students at 45 institutions, we derived five measures of learning outcomes in transition-themed first-year seminars and investigated their impact on intent to persist. Although all five are common components of first-year seminars, only two of the five measures, study skills and academic engagement, and health education, have substantial impact on early intention to persist.

By aggregating individual perceptions of first-year seminar effectiveness, we created a school-level measure of first-year seminar effectiveness that is separate from an individual student's perception. By including both measures in the model, we estimated the impact of both individual and school-wide perceptions of seminar effectiveness, finding that the aggregate measures for learning skills and health education had 
both statistically and substantively significant impacts on intent to persist to the second year of college.

That the school-level study skills and academic engagement factor is associated with higher intention to persist is consistent with the undergirding philosophy of many first-year seminars: students need assistance with college-level study and academic expectations. It makes intuitive sense that students who quickly gain confidence in their study skills would believe that they are likely to be successful in college and so plan to continue their enrollment.

It may be less clear why health education, like study skills, has an immediate payoff, but health education may be particularly important to first-year students for other reasons. Students commonly worry about their health and so might be particularly appreciative of new knowledge about how to handle self-maintenance as many are living away from home for the first time. We would hope that knowledge about health could be converted into actions which caused first-year students to feel better and perform better as students. We speculate, however, that the real value may be that when faculty spend classroom time on wellness issues they are de facto expressing caring about students. First-year seminars may have a positive impact on persistence when teaching health topics because of the knowledge conveyed or the acknowledgment that students are more than "cognitive beings."

That the school-level measures of college knowledge, peer connections, and co-curricular engagement are not highly associated with early intent to persist may simply be a reflection of the timing of the data collection, or perhaps these issues were addressed in many ways so that first-year seminars are not viewed by students as the key source of these topics. Such views would be consistent with widely held beliefs about first-year seminars. First, seminars often seek to prepare students for future collegiate decisions by "planting seeds" that are not expected to immediately produce fruit. Second, seminars are often a kind of "insurance" that all students receive key information even though it is provided through a number of other venues.

It is important to remember that we investigated the impact on early intention to persist. As noted, early intention is associated with ultimate persistence, but we cannot rule out factors that are important to later persistence decisions and might not be important to early decisions. For example, we would expect that knowing about campus rules would, in the long run, be a necessary component of a sense of comfort and integration into an institution.

What is also striking about these findings is that faculty often report that their least favorite part of first-year seminars is teaching study 
skills, and that the area they feel least prepared for is the counseling aspects of helping students develop holistically. Yet the two most important links to early intention to persist appear to be exactly these two issues. If institutions want their first-year seminars to be effective in impacting persistence, they must understand both the long- and shortterm effects of the choices faculty members make as they create their course syllabi. The selection of topics for an effective first-year seminar can be carefully orchestrated to create the kinds of outcomes that best match the institutional goals for the course. Effective course content on study skills and health education are too important to persistence to be ignored by those who administer and teach first-year seminars to first-year students.

\section{REFERENCES}

Allison, P. D. (2002). Missing Data Sage Publications, Thousand Oaks, CA.

Astin, A. (1993 September). College retention rates are often misleading. Chronicle of Higher Education.

Barefoot, B. O. (2000) The first-year experience: Are we making it any better? About Campus, 12-18.

Barefoot, B. O., Warnock, C. L., Dickinson, M. P., Richardson, S. E., and Roberts, M. R. (1998). Exploring the Evidence: Reporting the Outcomes of First-year Seminars (Vol. II) ((Monograph No. 25) ed.) University of South Carolina, National Resource-Center for The First-Fear Experience and Students in Transition, Columbia, SC.

Bean, J. (1982). Student attrition, intentions and confidence: Interaction effects in a path model. Research in Higher Education 17: 291-319.

Bedford, M. H., and Durkee, P. E. (1989). Some more ideas. NASPA Journal 27: 16-8171.

Blackhurst, A. E. (1995). The relationship between gender and student outcomes in freshman orientation courses. Journal of the Freshman Year Experience 7(2): 63-80.

Cabrera, A. F., Castaneda, M. B., Nora, A., and Hengstler, D. (1992). The convergence between two theories of college persistence. Journal of Higher Education 63(2): 143-164.

Cabrera, A. F., Nora, A., and Castaneda, M. B. (1992). The role of finances in the persistence process: A structural model. Research in Higher Education 33(5): 571-593.

Cannici, J. P., and Pulton, J. (1990). Personal competency training as a preventive intervention. Journal of the Freshman Year Experience 2(3): 31-43.

Chapman, L. C., and Reed, P. J. (1987). Evaluation of the effectiveness of a freshman orientation course. Journal of College Student Personnel 28: 178-179.

Choy, S. P. (2002). Access \& Persistence: Findings from 10 years of Longitudinal Research on Students American Council on Education, Washington, DC.

Cuseo, J. B. (1991). The Freshman Orientation Seminar: A Research-based Rationale for its Value, Delivery, and Content ((Monograph No. 4) ed.) University of South Carolina, National Resource Center for the Freshman Year Experience, Columbia, SC.

Davis, B. O. (1992). Freshman seminar: A broad spectrum of effectiveness. Journal of the Freshman Year Experience 4(1): 79-94. 
Davis-Underwood, M., and Lee, J. (1994). An evaluation of the University of North Carolina at Charlotte freshman seminar. Journal of College Student development 35: 491-492.

Fidler, P. P. (1991). Relationship of freshman orientation seminars to sophomore return rates. Journal of the Freshman Year Experience 3(1): 7-38.

Fidler, P. P., and Moore, P. S. (1996). A comparison of the effects of campus residence and freshman seminar attendance on freshman dropout rates. Journal of the Freshman Year Experience and Students in Transition 8(2): 7-16.

Gardner, J. N. (1986). The freshman year experience. College and University 61: 261-274.

Gordon, V. N. (1989). Origins and purposes of the freshman seminar. In: Upcraft, M. L., and Gardner, J. N. (eds.), The Freshman Year Experience: Helping Students Survive and Succeed in College, Jossey-Bass, San Francisco, pp. 183-197.

Heck, R. H., and Thomas, S. L. (2000). An Introduction to Multilevel Modeling Techniques Lawrence Erlbaum Associates, Mahwah, NJ.

Hoffman, D. A., and Gavin, M. B. (1998). Centering decisions in hierarchical linear models: Implications for research in organizations. Journal of Management 24(5): 623-641.

Horn, L. (1998). Stopouts or stayouts? Undergraduates who leave college in their first year ((NCES 1999-087) ed.) U.S. Department of Education, National Center for Education Statistics, US. Government Printing Office, Washington, DC.

$\mathrm{Hu}, \mathrm{S}$., and Kuh, G. D. (2002). Being (dis)engaged in educationally purposeful activities: The influences of student and institutional characteristics. Research in Higher Education 43(5): $555-574$.

$\mathrm{Hu}, \mathrm{S}$., and Kuh, G. D. (2003a). Diversity experiences and college student learning and personal development. Journal of College Student Developnnent 44(3): 320-334.

Hu, S., and Kuh, G. D. (2003b). Maximizing what students get out of college: Testing a learning productivity model. Journal of College Student Development 44(2): 185-203.

$\mathrm{Hu}$, S., and John, E.P. St. (2001). Student persistence in a public higher education system: Understanding racial and ethnic differences. Journal of Higher Education 72(3): 265-286.

Hyers, A. D., and Joslin, M. N. (1998). The first-year: seminar as a predictor of academic achievement and persistence. Journal of the First-Year Experience and Students in Transtion 10(1): 7-30.

Jonge, J. d., Gerard, J. P. v. B., Landeweerd, J. A., and Nijhuis, F. J. N. (1999). Comparing groups and individual level assessments of job characteristics in tesing the job demandcontrol model: A multilevel approach. Human Relations 52(1): 95-121.

Kim, M. M., Rhoades, G., and Woodard, D. (2003). Sponsored research versus graduating students? Intervening variables and unanticipated findings in public research universities. Research in Higher Education 44(1): 51-82.

Kuh, G. D., and Hu, S. (2001). The effects of student-faculty interaction in the 1990s. Review of higher Education 24(3): 309-332.

Leppel, K. (2002). Similarities and differences in the college persistence of men and women. Review of Higher Education 25(1): 433-451.

Maisto, A. A., and Tammi, M. W. (1991). The effect of content-based freshmen seminar on academic and social integration. Journal of Freshman Year Experience 2: 29-48.

Merlo, J., Ostergren, P. -O., Hagberg, O., Lindstrom, M., Lindgren, A., and Melander, A., (2001). Diastolic blood pressure and area of residence: Multilevel versus ecological analysis of social inequity. Journal of Epidemiology and Community Health 55(11): 791-798.

Murtuza, A., and Ketkar, K. W. (1995). Evaluating the cost-effectiveness of freshman year programs on an urban campus. Journal of the Freshman Year Experience 7(1): 7-26.

National Resource Center for the First-Year Experience and Students in Transition (2002). The 2000 National Survey of First-year Seminar Programs: Continuing Innovations in the Collegiate Curriculum ((Monograph No. 35) ed.) University of South Carolina, Columbia, SC. 
Nelson, R. B., Scott, T. B., and Bryan, W. A. (1984). Precollege characteristics and early college experiences as predictors of freshman year persistence. Journal of College Student Personnel 25(1): 50-54.

Okun, M. A., Benin, M., and Brandt-Williams, A. (1996). Staying in college: Moderators of the relation between intention and institutional departure. Journal of Higher Education 67(5): 577-596.

Pascarella, E. T., and Terenzini, P. T. (1991). How college affects students: Findings and insight from twenty years of research Jossey-Bass, San Francisco.

Policy Center on the First Year of College. (2002) Second National Survey of First-Year Academic Practices 2002 [Web Page]. URL www.brevard.edu/fyc/survey 2002 [2003, May 12].

Porter, S. R. (2000). The robustness of the graduation rate performance indicator used in the U.S. News and World Report college rankings. International Journal of Educational Advancement 1(2): 145-164.

Mortenson, T. G. (2001). Where the guys are not: The growing gender imbalance in college degrees awarded. Postsecondary Education Opportunity 104: 1-11.

Raudenbush, S. W., and Bryk, A. S. (2002). Hierarchical linear models: Applications and data analysis methods Sage Publications, Thousand Oaks, CA.

Ryan, J. F. (2004). The relationship between institutional expenditures and degree attainment at baccalaureate colleges. Research in Higher Education 45(2): 97-114.

Snijders, T. A. B., and Bosker, R. J. (1999). Multilevel analysis Sage Publications, Thousand Oaks, CA.

Strumpf, G., and Hunt, P. (1993). The effects of an orientation course on the retention and academic standing of entering freshmen, controlling for the volunteer effect. Journal of the Freshman Year Experience 5(1): 7-14.

Tinto, V. (1975). Dropout from higher education. Review of Educational Research 45: 89-125.

Tinto, V. (1993). Leaving college: Rethinking the causes and cures of student attrition (2nd Ed.) University of Chicago Press, Chicago.

Toutkoushian, R. K., and Smart, J. C. (2001). Do institutional characteristics affect student gains from college? Review of Higher Education 25(1): 39-61.

U.S. Department of Education (2001). High School Academic Curriculum and the Persistence Path through College: Persistence and Transfer Behavior of Undergraduates 3 Years after entering 4-year Institutions (NCES 2001-163) National Center for Educational Statistics, Washington, DC.

U.S. News and World Report (2002). Programs that Really work. U.S. News and World Report 11: 104.

Williford, A. M., Chapman, L. C., and Kahrigh, T. (2000-2001). The university experience course: A longitudinal study of student performance, retention, and graduation. Journal of College Student Retention 2(4): 327-340.

Zhao, C. -M., and Kuh, G. D. (2004). Adding value: Learning communities and student engagement. Research in Higher Education 45(2): 115-138.

Received August 17, 2003. 